\title{
Characterizing Transient Measurements by Use of the Step Response and the Convolution Integral
}

\author{
RONALD H. MCKNIGHT, JOHN E. LAGNESE, AND YI XIN ZHANG
}

\begin{abstract}
A method to determine the suitability of a divider system for making measurements of high voltage transients is described. This method involves the convolution of the experimentally determined step response of the divider with various analytic waveforms which represent ideal waveforms expected in the experimental arrangement. The result of the convolution is compared, both graphically and in terms of relevant parameters such as peak amplitude and front time, with the original waveform. This procedure allows the distortion introduced by the convolution calculation to be seen clearly. The numerical implementation of the method is easily run on a personal computer.
\end{abstract}

\section{INTRODUCTION}

$\mathrm{T}$ HE MEASUREMENT of high voltage transients requires a means of reducing the high voltage signal to levels which are compatible with data recording equipment. The measurement devices which accomplish this reduction are known generically as voltage dividers and ideally they should scale the signal to a smaller value without distortion. These dividers, however, invariably introduce some distortion of the input signal, due primarily to inadequate bandwidth or aberrations such as overshoot. This distortion may be negligible or totally unacceptable, depending on the allowable error associated with the particular measurement requirement. One example of the type of distortion encountered in cascading systems is the effect on rise time, which can be calculated for certain conditions by using the well-known root-mean-square expression, $\tau_{\mathrm{eff}}=\left(\tau_{1}^{2}+\tau_{2}^{2}+\cdots\right)^{1 / 2}$ where the individual rise times are those of the cascaded system [1]. It should be noted that this calculation is frequently applied inappropriately, since it applies only to cascaded systems whose components have monotonic transitions.

If the divider system is assumed to be linear, then the general methods of linear system analysis can be applied to characterize the system. Two equivalent approaches involve either time- or frequency-domain analysis. In the frequency domain [2], the divider is characterized by the following equation:

$$
\left(\begin{array}{c}
V_{\mathrm{in}}(\omega) \\
I_{\mathrm{in}}(\omega)
\end{array}\right)=\left(\begin{array}{cc}
A_{11}(\omega) & A_{12}(\omega) \\
A_{2 !}(\omega) & A_{22}(\omega)
\end{array}\right)\left(\begin{array}{c}
V_{o}(\omega) \\
I_{o}(\omega)
\end{array}\right) .
$$

Manuscript received August 23, 1989.

R. H. McKnight is with the Experimental Plasma Research Branch, U.S Department of Energy, Washington, DC 20545.

J. E. Lagnese is with Electrosystems Division, National Institute of Standards and Technology, Gaithersburg, MD 20899.

Y.X. Zhang is with the Wuhan High Voltage Research Institute, Wuhan Hubei, China.

IEEE Log Number 8933804
The voltage transfer function, $H(\omega)$, is defined for zero output current, $I_{o}=0$, i.e.:

$$
H(\omega)=\left.\frac{V_{o}(\omega)}{V_{\text {in }}(\omega)}\right|_{I_{o}(\omega)=0}=\frac{1}{A_{11}(\omega)} .
$$

The conventionally defined divider ratio is given by

$$
N=A_{11}(0)=\lim _{\omega \rightarrow 0} A_{11}(\omega)
$$

if the limit exists. For some dividers-capacitive dividers for example-the limit does not exist and the ratio is defined for a region of little change in $A_{11}(\omega)$. In general, the elements of the matrix are complex numbers containing both amplitude and phase information. Clearly, one of the requirements in analyzing the divider in terms of its frequency response is the ability to measure that response. In practice, however, this is not an easy task [2]. Since it is not practical to provide a complete response curve, some limits must be applied and these limits must be based on an understanding of the divider response.

In the time domain, the divider characteristics are incorporated in the impulse response. Under the assumption that the system is linear, causal, and time-shift invariant, the input and output voltages are related through the convolution integral (also known as Duhamel's integral [3], [4]), given in:

$$
\begin{aligned}
v_{o}(t) & =\int_{0}^{t} v_{\text {in }}(s) g(t-s) d s \\
& =\frac{d}{d t} \int_{0}^{t} v_{\text {in }}(s) u(t-s) d s
\end{aligned}
$$

where $g(t-s)$ is the system impulse response and $u(t$ $-s$ ) is the step response.

It is generally not feasible to measure the impulse response directly. Because of the impulse and step response relationship indicated in (4), the step response can be used to characterize the system. This approach is attractive for many laboratories, since the transient recording device required to make the measurements can also be used to record the step response if the bandwidth, sampling rate, etc., are adequate.

The use of the step response to characterize systems for high voltage measurements is detailed as a part of both IEEE and IEC standards [5], [6] concerned with the measurement of standard pulses used in the electrical power 
industry. In each, various parameters are obtained from a measured step response and are used to predict if a given measuring system is adequate to provide a measurement within the uncertainty limits specified by the standards. The step response is not used directly in the actual measurement and there has been much discussion, both published and in working group meetings, about the usefulness of the step response parameters in the existing standards [7]-[9]. The appropriate interpretation of the step response itself in real measuring systems was also extensively debated prior to and during the process of developing the existing standards [10]-[13]. Different parameters obtained from experimental step responses have been proposed as alternatives in the existing standards, and have generated much discussion but have not been adapted [7]. A proposed revision to the IEC standard recommends that the accuracy of the measurement be determined by use of a measuring system that has been compared to a reference system maintained by the appropriate national laboratory [14]. The results obtained from one international comparison of high voltage dividers have been described in the literature [15].

\section{Discussion of Proposed Method}

Described below is a method which uses experimentally determined step responses along with analytic waveforms to determine the suitability of a particular measuring system for making measurements of interest. The method involves the convolution of the experimental step response with an analytic waveform which represents the ideal waveform expected in the experimental arrangement, using (4). For example, for the full lightning waveform, this would be a double exponential with appropriate time constants. The same waveform would also be used for canonical EMP waveforms, with the appropriate change in time constants. Actual waveforms obtained from a measuring system which is known to introduce negligible errors can also be used in the calculation. The use of this method has been discussed at various times in working group meetings and one application is presented in a paper describing the comparison of two dividers [15]. Two earlier reports describe convolution calculations and their application to measurement analysis [16], [17]. In contrast to a calculation method which uses unrealistic signals such as ramps, the convolution method presented can show the effect of the use of a given measuring system, represented by its step response, to measure a signal of a shape closely related to the actual signals of interest. The use of this method and the plotting of input and output waveforms is instructive in that the distortion is clearly seen.

It should be emphasized that this method does not address some of the questions raised in historical debate about the step response itself and the methods of obtaining it. The measurement must be done properly and the individual experimenter must have sufficient expertise and knowledge to insure this. The damping conditions resulting from the internal impedance of the test generator and any external damping resistance in general are not known. As a result, only bounds can be placed on the measurement using this method. Considerations of data recording system requirements are beyond the context of the present work and are not discussed here. It should be noted that the convolution technique described here should not be confused with the deconvolution process in which the integral, (4), is solved for the input signal when the output and the system impulse (step) response are known. The mathematical difficulties associated with deconvolution are well documented and have been discussed in the literature along with measurement problem applications [18], [19].

Values of waveform parameters such as peak-value and virtual front-time, for standard or chopped lightning waveforms (defined in the existing IEC and IEEE standards), or rise time (appropriately defined), and peak value for an arbitrary waveform, can be determined for both the input and calculated output waveform. By comparing the values, the error introduced by the measuring system can be estimated. This estimate should not be considered a correction factor, but rather an uncertainty bound on the actual measurement and an estimate of the best measurement that can be made with a given system for the assumed waveform. Systematic errors, random noise, and other confounding factors will further degrade the quality of the measurement.

\section{Experimental Method}

Two dividers, referred to as NBS1 and NBS3, have been used at the National Institute of Standards and Technology (NIST) for measurements of transient voltages. More recently, a third divider, NBS4, was developed to provide a reference quality system. It has a nominal ratio of $10^{4}: 1$, is oil insulated with an overall dimension of $0.83 \mathrm{~m}$, and is rated for 300-kV full lightning impulse. Step responses for a variety of conditions were obtained for all three dividers using procedures detailed in [20]. The parameter varied in these measurements was the damping resistor, referred to as $R_{d}$ below.

For voltage measurement systems installed in devices such as gas-insulated power equipment or pulse-power systems, as opposed to free standing devices, the main difficulty in applying step response measurement methodology is that of producing a fast step in the equipment. Producing this step has been done in several ways including charging the system and then shorting the system to ground through an existing switch or through a switch installed for the test. In some test lines or systems with specific geometries, it may be possible to apply a step from an external generator and observe the wave propagating on the line by means of the installed sensor. An example of this approach, done in a test line designed to evaluate fast sensors, is described in [21]. Sensors used to measure transients in gas-insulated power equipment and pulsepower systems, for example, have been subjected to stepresponse evaluation and several examples have been published. Input and output step waveforms for voltage di- 
viders designed for use in gas insulated equipment are included in [22]. A fast divider, a fast current probe, and a subnanosecond attenuator are similarly characterized in [23]-[25]. These "evaluations" are qualitative and basically attempt to show that the step-response of the system has a transition time much faster than the anticipated signal to be measured, as well as some modest degree of overshoot, contributing to an acceptable error in the actual measurement.

\section{Convolution Calculations}

The functional form of the double exponential voltage waveform used in these calculations is given in (5), where the parameters $\alpha$ and $\beta$ for four different waveforms are given in Table I:

$$
v(t)=A(\exp (-\alpha t)-\exp (-\beta t)) .
$$

In (5), $A$ is a normalizing factor. A standard lightning waveform designated by a " $T 1 \times T 2$ " statement refers to a waveform which has an approximate front time of $T 1$ and a time $T 2$ to decay to 50 percent of the peak value, measured from the peak. The two fast waveforms in Table I are used to represent particular waveforms of interest to workers studying the effects of fast transients on various equipment. The first is roughly a "50 ns $\times 500 \mathrm{~ns}$ ", waveform, while the second is a canonical waveform frequently used in EMP calculations. Two different standard lightning waveforms were used. One had front and fall times near the standard $1.2 \mu \mathrm{s} \times 50 \mu \mathrm{s}$ waveform, while the second had a faster front time. In addition to the full waveform, chopped waveforms were also used in the calculations. For these, the standard waveforms were disrupted at some fraction of the peak value and brought linearly to zero in a chosen time, typically 50 or 100 ns.

The experimentally determined step responses and a digitized representation of the input waveform were used in the convolution calculations. The calculation is straightforward and can be done on a personal computer. An example of a convolution is displayed in Fig. 1 where both input and output waveforms are shown for the NBS1 divider configured for near critical damping. This represents the slowest response time measured for the divider. In Fig. 1 and all subsequent comparison figures, the input waveform has been normalized to have a peak value of 1 . In the following figures, the measured step responses for the individual dividers are displayed together with the input (analytic) waveform and the result of the convolution.

Similar calculations for a chopped waveform and the same divider configuration are shown in Fig. 2. These calculations illustrate the distortion introduced in the output waveform as a result of the inadequate dynamic response of the divider. As is well known, the chopped waveform is significantly more difficult to measure accurately than is the full lightning waveform. The new NIST system, NBS4, was designed to have a response time such that negligible distortion is introduced by the divider itself. The convolution of the critically damped step response for this divider, with the same input waveform
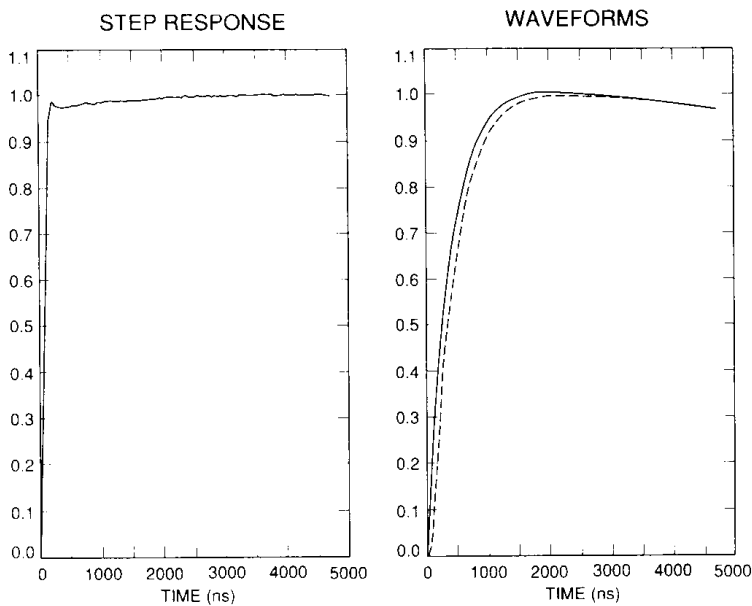

Fig. 1. Convolution of the measured step response shown for NBS1 con figured to be near critically damped with the nominal $1.2 \mu \mathrm{s} \times 50 \mu \mathrm{s}$ analytic waveform of Table I. Input waveform is solid, convolution output dashed.
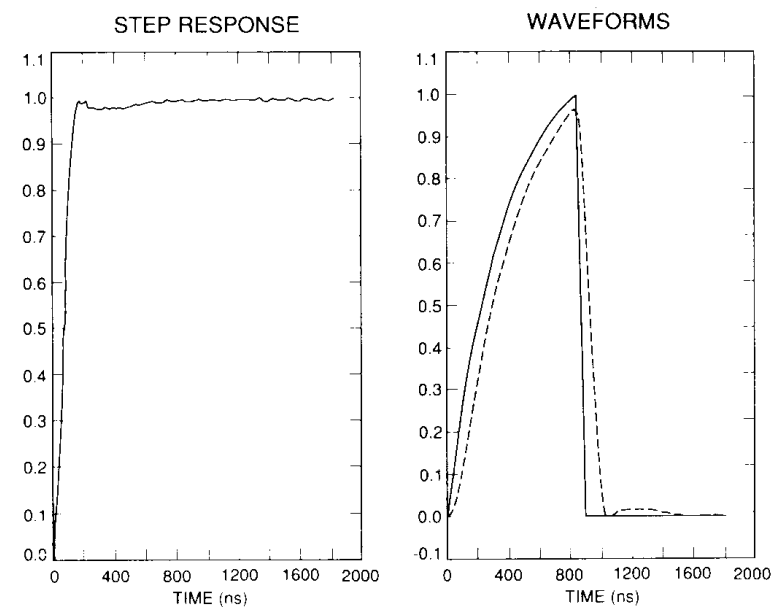

Fig. 2. Convolution of the same step response (NBS1) as in Fig. 1 with a chopped waveform. Chop was at 90 percent of the full waveform peak and the chop was a linear 50-ns ramp to zero. The input waveform was renormalized to 1 for presentation.

TABLE I

Parameter Values for Selected Waveforms

\begin{tabular}{ccc}
\hline Wareform & 0 & 3 \\
$\left(s^{-1}\right)$ & $\left(s^{-1}\right)$
\end{tabular}

Staulard $1.2 \times 50 \quad 1.46 \times 10^{4} \quad 2.47 \times 10^{\text {i }}$

Standard $0.9 \times 50 \quad 1.44 \times 10^{-4} \quad 3.35 \times 10^{6}$

Fast Waveform $1 \quad 1.70 \times 10^{6} \quad 48.5 \times 10^{6 \mathrm{i}}$

Fast Wawform $24.0 \times 10^{6} \quad 476 \times 10^{6}$

used in Fig. 2 for the critically damped NBS1, is displayed in Fig. 3. A series of calculations for the different configurations of the three dividers using various waveforms are summarized in Tables II and III, where front times and peak values (normalized) as defined in [5] are shown. The damping resistor values result in step re- 

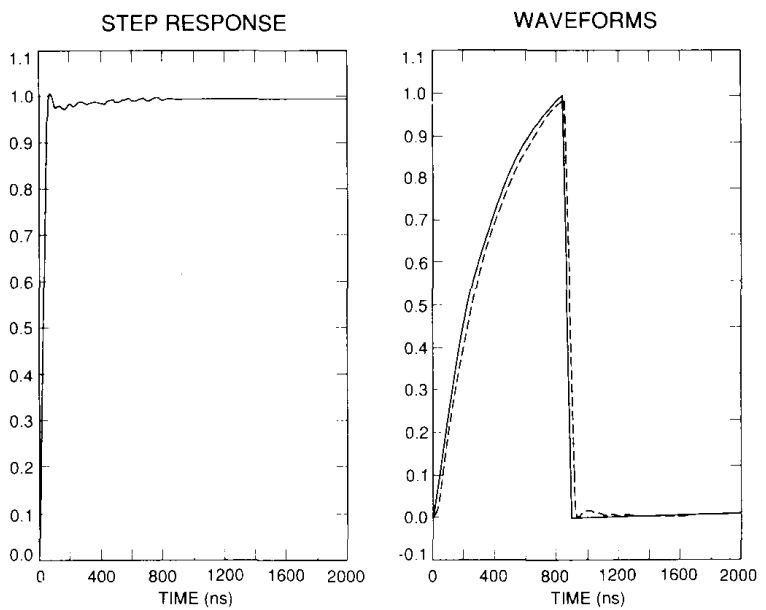

Fig. 3. Convolution of the step response obtained for NBS4 in a critically damped configuration with the same input waveform as in Fig. 2.

TABLE II

Calculation of Distortion INTRODUCEd by Various Divider CONFIGURATIONS FOR FULL LIGHTNING IMPULSE

\begin{tabular}{|c|c|c|c|c|c|}
\hline Divider & $\operatorname{Rd}(\Omega)$ & $\begin{array}{c}\text { Actual } \\
\text { Front Time }\end{array}$ & $\begin{array}{l}\text { Calculated } \\
\text { Frout Tine }\end{array}$ & $\begin{array}{c}\text { Actual } \\
\text { Pcak Value }\end{array}$ & $\begin{array}{l}\text { Calculated } \\
\text { Peak Value }\end{array}$ \\
\hline NBS1 & 0 & $1.2 \mu \mathrm{s}$ & $1.33 / 1 \mathrm{~s}$ & 1.0 & 0.995 \\
\hline NBS1 & 250 & 1.2 & 1.26 & 1.0 & $0.99 \overline{-}$ \\
\hline ХBS1 & 400 & 1.2 & $1.2 \bar{i}$ & 1.0 & 0.994 \\
\hline NBS3 & 0 & 1.2 & $1.2 \mathrm{~S}$ & 1.0 & 0.995 \\
\hline NBS3 & 250 & 1.2 & 1.21 & 1.0 & 1.0 \\
\hline NBS3 & 550 & 1.2 & 1.21 & 1.0 & 1.0 \\
\hline XBS1 & 0 & 0.9 & 0.94 & 1.0 & 0.995 \\
\hline NBS1 & 250 & 0.9 & 0.95 & 1.0 & 0.995 \\
\hline ×BS1 & 400 & 0.9 & 0.95 & 1.0 & 0.991 \\
\hline$\triangle B S 3$ & 0 & 0.9 & 0.95 & 1.0 & 0.992 \\
\hline NBS3 & 250 & 0.9 & 0.92 & 1.0 & 1.0 \\
\hline NBS3 & 550 & 0.9 & 0.92 & 1.0 & 1.0 \\
\hline NBS4 & 0 & 0.9 & 0.92 & 1.0 & 1.0 \\
\hline NBS4 & 250 & 0.9 & 0.92 & 1.0 & 1.0 \\
\hline NBS4 & 500 & 0.9 & 0.92 & 1.0 & 1.0 \\
\hline
\end{tabular}

sponses which range from no damping to approximately critical damping for each divider. Two different chopped waveforms were used for illustration. The values presented with front times of about $1 \mu \mathrm{s}$ were calculated using the $1.2 \mu \mathrm{s} \times 50 \mu \mathrm{s}$ waveform chopped at 0.9 of the peak value. Those with the shorter front times represent a chop at 0.75 of the peak value of the $0.9 \mu \mathrm{s} \times 50 \mu \mathrm{s}$ waveform. This second waveform represents an extreme condition and would not realistically be used in measurements. These calculations illustrate the errors that can be expected as a divider's dynamic response becomes inadequate. For full lightning impulses, these results indicate that the three dividers would be expected to provide accurate measurements. Front times show larger differences, in part due to uncertainty in calculating front times when there are superimposed oscillations. For the
TABLE III

Calculation of Distortion Introduced by Various Divider CONFIGURATIONS FOR CHOPPED LIGHTNING IMPULSE

\begin{tabular}{|c|c|c|c|c|c|}
\hline Divider & $R d(\Omega)$ & $\begin{array}{c}\text { Actual } \\
\text { Front Time }\end{array}$ & $\begin{array}{l}\text { Calculated } \\
\text { Front Time }\end{array}$ & $\begin{array}{c}\text { Actual } \\
\text { Peak Value }\end{array}$ & $\begin{array}{l}\text { Calculated } \\
\text { Peak Value }\end{array}$ \\
\hline NBS1 & 0 & $0.98 \mu \mathrm{s}$ & $0.98 \mu \mathrm{s}$ & 1.0 & 0.990 \\
\hline NBS1 & 250 & 0.98 & 0.92 & 1.0 & $0.96 \mathrm{~s}$ \\
\hline NBS1 & 400 & 0.98 & 0.91 & 1.0 & 0.969 \\
\hline NBS3 & 0 & $0.9 \mathrm{~S}$ & 0.96 & 1.0 & 0.980 \\
\hline NBS3 & 250 & 0.98 & 0.95 & 1.0 & 0.954 \\
\hline NBS3 & 550 & 0.98 & 0.94 & 1.0 & 0.982 \\
\hline NBS1 & 0 & 0.43 & 0.40 & 1.0 & 0.923 \\
\hline NBS1 & 250 & 0.43 & $0.3 \mathrm{~s}$ & 1.0 & 0.910 \\
\hline XBS1 & 400 & 0.43 & $0.3 T$ & 1.0 & $0.89 \bar{T}$ \\
\hline NBS3 & 0 & 0.43 & 0.42 & 1.0 & 0.962 \\
\hline NBS3 & 250 & 0.43 & 0.41 & 1.0 & 0.949 \\
\hline NBS3 & 550 & 0.43 & 0.40 & 1.0 & $0.94 \overline{5}$ \\
\hline NBS4 & 0 & 0.43 & 0.44 & 1.0 & 0.980 \\
\hline NBS4 & 250 & 0.43 & 0.43 & 1.0 & 0.972 \\
\hline NBS4 & 500 & 0.43 & 0.42 & 1.0 & 0.964 \\
\hline
\end{tabular}

chopped-lightning measurements, the differences become much more significant. In a recently completed international comparison of impulse measuring systems, experimental results were obtained which were consistent with these calculations [15].

Convolution calculations can also be used to show clearly that superficial deductions and anecdotal statements based on observations of step response measurements may be misleading. For example, a theoretical step response was devised in which there was significant overshoot and severe oscillations of varying frequency. The three step responses used in the calculations are shown in Fig. 4. The overshoot is extreme (about 80 percent), while the resonant frequencies of the system ranged from 5 to $16 \mathrm{MHz}$. Fig. 4 shows convolutions of the empirical step responses with a $0.9 \mu \mathrm{s} \times 50 \mu \mathrm{s}$ waveform chopped at 90 percent of the peak, with a 100 -ns collapse. Clearly, both the step response of the measuring system and the waveform to be measured are important in the calculation.

These calculations also illustrate a problem of practical concern in the measuring laboratory and one which is inadequately dealt with in the present standards. The oscillations on the front of the output waveform make a calculation of the time parameters, such as transition times based on percentages of the waveform (front time or rise time), subject to considerable error.

The limitations posed by the use of conventional freestanding dividers to measure pulses faster than those typically used by the electrical power community are shown in Fig. 5. Here, the waveform is the fast waveform 1 from Table I and the step response is that of the NBS3 divider configured with no damping resistor. The resulting oscillatory output makes this measurement useless. In contrast, Fig. 6 shows the same waveform with a critically damped response. Despite the very large error introduced 
STEP RESPONSE

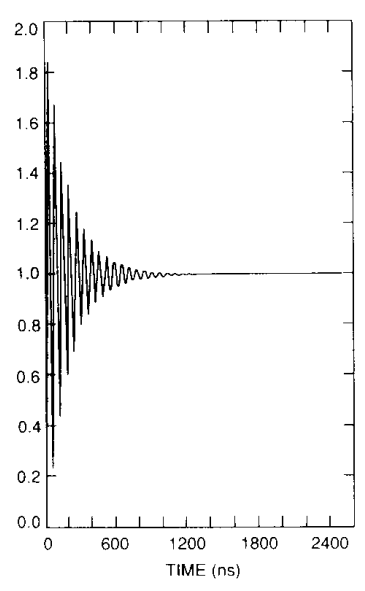

STEP RESPONSE

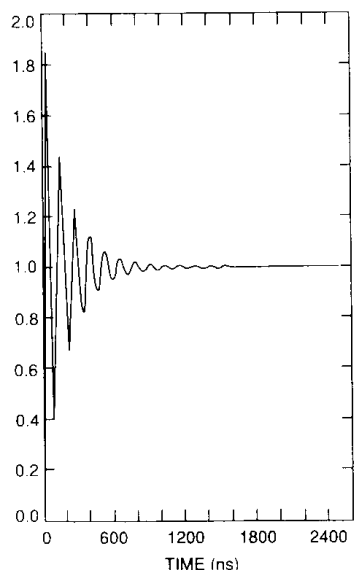

TEP RESPONSE

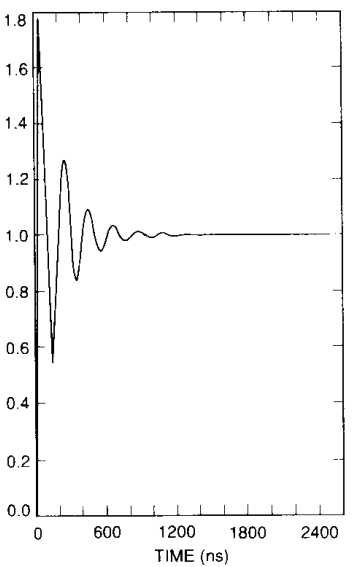

(c)

Fig. 4. Convolutions of a chopped waveform (see text) with empirical step responses calculated to show effects of ring frequency. Overshoot in each case was approximately 80 percent, and the ring frequencies were approximately (a) $16 \mathrm{Mhz}$; (b) $8 \mathrm{Mhz}$; (c) $4.8 \mathrm{Mhz}$. The settling time was adjusted to be slightly more than $1 \mu \mathrm{s}$. The input waveform is solid, the output dashed.
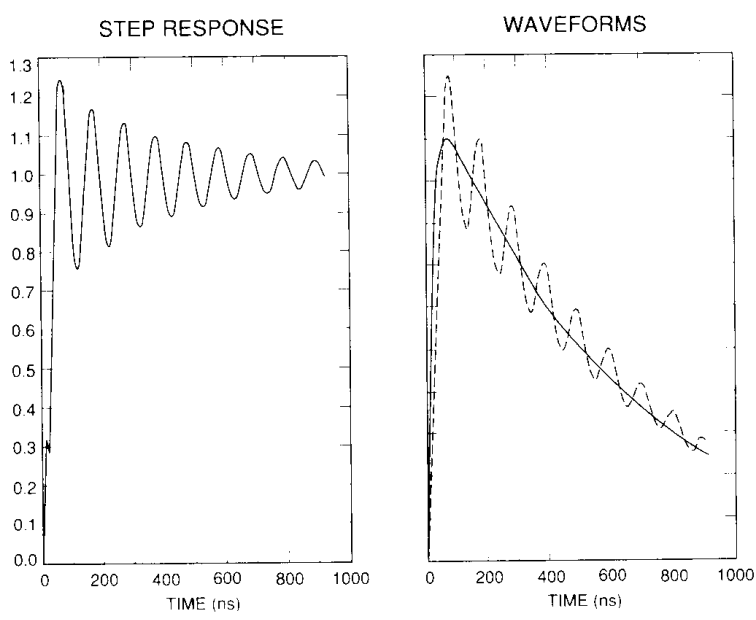

Fig. 5. Convolution of fast waveform 1 (Table l) with an undamped step response for NBS3. Observed overshoot is approximately 15 percent. The input is solid, the output dashed.
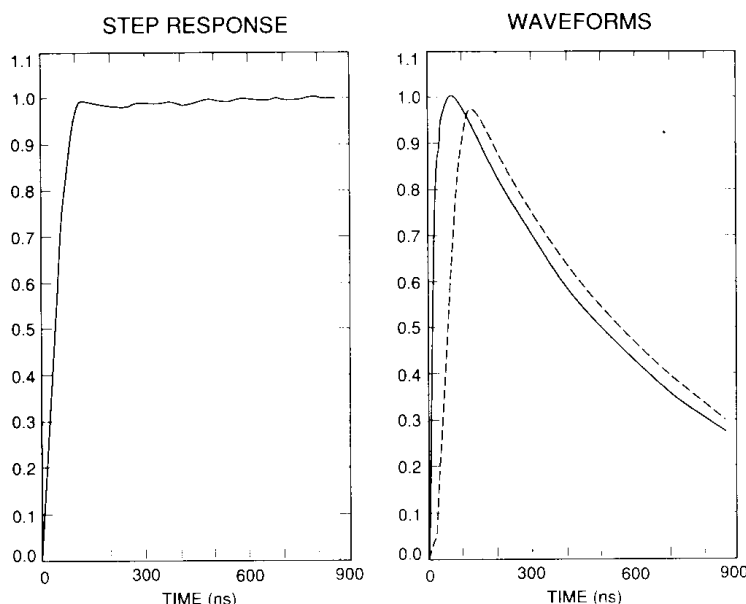

Fig. 6. Fast waveform 1 convolved with a critically damped step response for NBS3. The input is solid, the output dashed.

in the front time of the waveform due to the inadequate divider response, the error in the peak value is much smaller. Of course, faster dividers can be constructed for these waveforms, but as the required voltage increases this becomes more difficult. In order to obtain a comparison between two dividers with significantly different step responses, Figs. 7 and Fig. 8 display the convolution for undamped and critically damped responses for NBS4 with fast waveform 1. These should be compared with Figs. 5 and 6 , respectively (note change of time scale).

As an example of the error that can be introduced in the peak value of a waveform, consider the convolution of fast waveform 2 (Table I) with the step response of the small resistive divider characterized in [20] as illustrated in Fig. 9. Although the step response of the divider is almost adequate to follow the waveform, the overshoot produces a significant error. This is an example of a sit- 
STEP RESPONSE

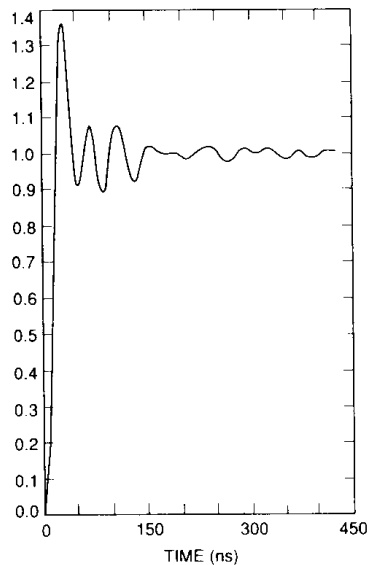

Fig. 7. Fast waveform 1 convolved with an undamped step response for NBS4. The input is solid, output dashed.
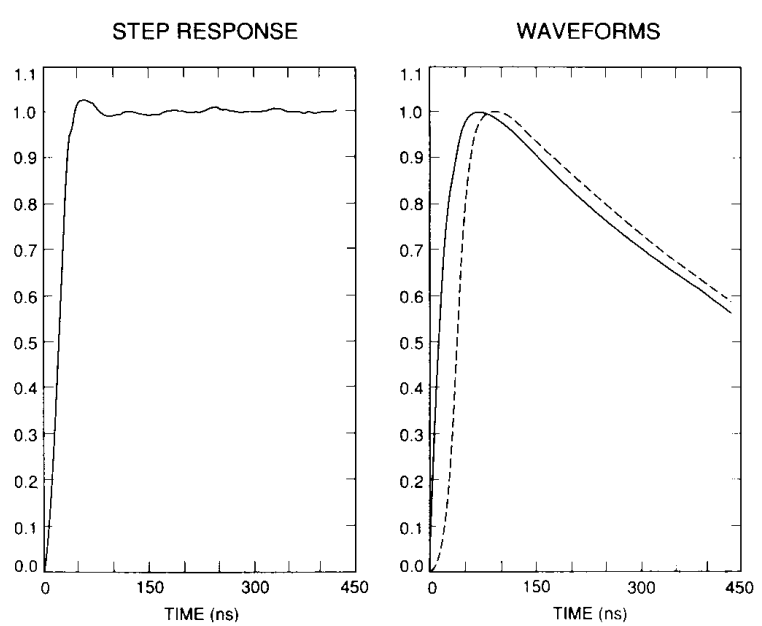

Fig. 8. Fast waveform 1 convolved with a critically damped step response for NBS4. The input is solid, output dashed.

uation where the convolution can be used to judge if the potential error is excessive for the intended measurement.

An additional question concerning the use of the step response is the effect of the closure speed switch on the step response measurement. A series of convolutions have been done in which ramps of different 0 -100-percent rise times ranging from 1 to $60 \mathrm{~ns}$ (for this calculation) were used with an arbitrarily chosen experimental step response for NBS1. The measured step response and its convolution with a ramp step of $60 \mathrm{~ns}$ is shown in Fig. 10. Although the distortion of the step response shown in Fig. 10 is significant, the calculations indicate that for this step response, switch closure times as long as $20 \mathrm{~ns}$ had little effect on the step response. This implies that for many dividers designed to measure standard lightning impulses, switches other than the fast mercury relays could be used. This may decrease some of the "noise" prob-
STEP RESPONSE

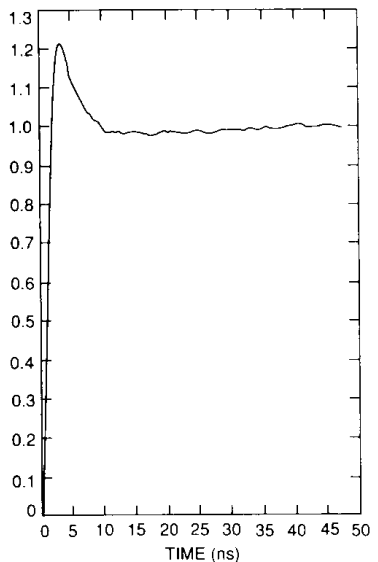

WAVEFORMS

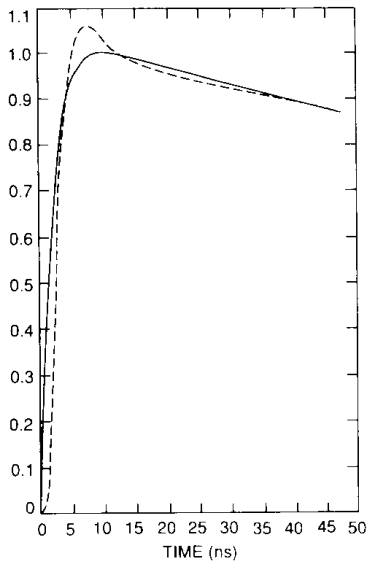

Fig. 9. Fast waveform 2 (Table I) convolved with the step response of the small resistive divider.
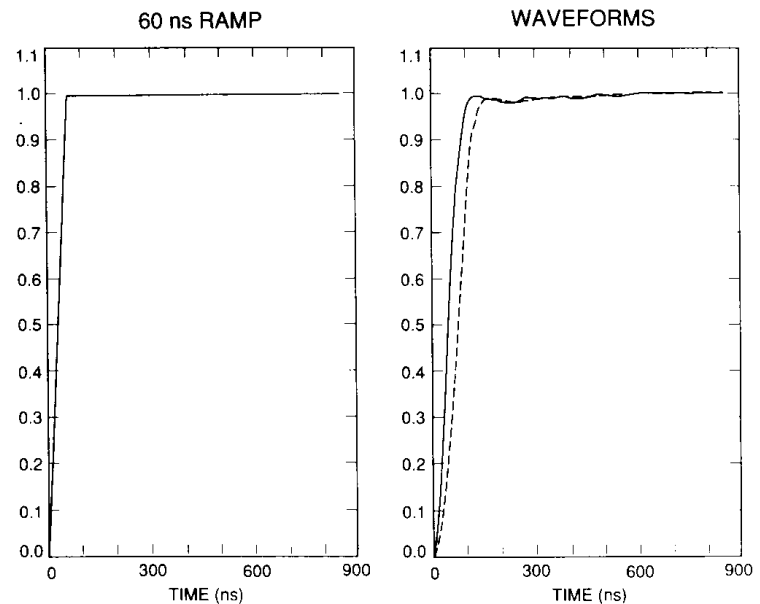

Fig. 10. Distortion of step response of critically damped NBSI divider by convolution with a $60 \mathrm{~ns}(0-100$ percent $)$ ramp. Solid curve is undistorted step, dashed result of calculation.

lems resulting from radiation effects associated with fast rise times [2].

\section{Conclusions}

The examples of convolution calculations described in this report illustrate a method of evaluating high voltage measurement systems and are not intended to be exhaustive. Each laboratory would have to measure the step response of its own system by devising a method to produce a step to which the measuring system would respond. For free-standing dividers, the methods outlined in the standards listed previously or those discussed in the literature will suffice. Earlier technical problems were encountered in generating a step with a fast transition time at sufficiently high voltage to produce a signal adequate to register on the relatively insensitive impulse oscilloscopes. These difficulties have all but disappeared with the advent 
of fast, versatile, digital waveform recorders with low level inputs. Frequently the present day problem is one of attenuating the signal to usable levels during testing.

Waveforms of the type expected in the experiment can be calculated using a simple analytic form as illustrated here, or by using a lookup table in the calculation. An experimentally determined waveform, recorded by a divider known to introduce little distortion, could also be used.

As noted earlier, this approach should not be considered as a method for obtaining correction factors for a given measurement. It does appear to be useful, however, in providing an evaluation of the application of a given measurement method of known experimental step response to the measurement of well-characterized impulse waveforms.

\section{REFERENCES}

[1] W. C. Elmore. "The transient response of damped linear networks with particular regard to wideband amplifiers, "J Appl. Phys., vol. 19. pp. 55-63, 1948

[2] "IRR-IMS-Group: Facing UHV measuring problems," Electra, no. 35, July 1974

[3] W. R. Fowkes and R. M. Rowe, "Refinements in precision kilovolt pulse measurements," IEEE Trans. Instrum. Meas., vol. IM-15, pp. 284-292, 1966.

[4] A. V. Oppenheim, A. S. Willsky, and I. T. Young, Signals and Systems. Englewood Cliffs, NJ: Prentice-Hall Signal Processing Series, Prentice-Hall, 1983

15] IEEE Standard Techniques for High Voltage Testing, IEEE Standard 4,1978

[6] "International electrotechnical commission, high voltage test techniques," IEC Publication, vol. 60-64, 1973-1977.

[7] N. Hylten Cavallius and T. Parnell, "The measurement of standard lightning impulses," in Proc. Third Int. High Voltage Symp.. Milan. Italy, vol. 2, paper 42.05. Aug. 1979.

[8] Q. C. Qi and W. S. Zaengl, "Investigations of errors related to the measured virtual front time TA of lightning impulses," IEEE Trans. Power App. Syst., vol. PAS-102, pp. 2379-2390, 1983.

[9] N. Hylten Cavallius, F. A. Chagas, and A. Chakrabarti, "A new approach to minimize response errors in the measurement of high voltage impulses," IEEE Trans. Power App. Syst., vol. PAS-102. pp. 2077-2091, 1983.

[10] F. C. Creed and M. M. C. Collins, "The measurement of short-du- ration impulse voltages," IEEE Trans. Commun. Electron., vol. $-\mathrm{CE}$ 82 , pp. $621-630,1963$

[11] F. C. Creed, T. Kawamura, and G. Newi, "The step response of measuring systems for high impulse voltages," IEEE Trans. Power App. Syst., vol. PAS-86, pp. 1408-1420, 1967.

[12] A. Pedersen and P. Lausen, "Dynamic properties of impulse measuring systems," IEEE Trans. Power App. Syst., vol. PAS-90, pp $1424-1432,1971$

[13] F. C. Creed and M. M. C. Collins, "Transient impedance of highvoltage impulse generating systems," IEEE Trans. Power App. Syst. vol. PAS-89, pp. 1387-1393, 1970.

[14] "Prepared by WG7 of IEC/TC42 draft-high voltage test techniques," Revision of Publication 60-63 and 60-64.

[15] T. R. McComb, R. C. Hughes, H. A. Lightfoot, K. Schon, R. Schulte, R. H. McKnight, and Y. X. Zhang, "International comparison of HV impulse measuring systems," IEEE Trans. Power Delivery, vol. 4, pp. 906-915, 1989

[16] D. Kind, H. Korff, A. Schmidt, and K. Schon, "Chopping errors for characterizing HV impulse dividers," in Proc. Fifth Int. Symp. on High Voltage Engineering, Braunschweig, FRG, paper 71.02, 1987

[17] R. E. Hebner and S. Annestrand, "Evaluation of calibration techniques for multimegavolt impulse dividers," in Proc. Third Int. High Voltage Symp., Milan, Italy, vol. 2, paper-42.18, Aug. 1979.

[18] H. Link, "Discussion of reference 10 (this paper)," IEEE Trans. Power App. Syst., vol. PAS-86, pp. 1417-1418, 1967.

[19] J. Lagnese and R. H. McKnight, "Calculation of confidence intervals for high-voltage impulse reconstruction," IEEE Trans. Instrum. Meas., vol. 37, pp. 201-206, 1988.

[20] T. K. Sarkar, F. 1. Tseng, S. M. Rao, S. A. Danat, and B. Z. Hellman, "Deconvolution of impulse response from time-limited input and output: Theory and experiment," IEEE Trans. Instrum. Meas., vol. IM-34, pp. 241-246, 1985.

[21] Y. X. Zhang, R. H. McKnight, and R. E. Hebner, "Interactions between two dividers used in simultaneous comparison measurements," IEEE Trans. Power Delivery, vol. 4, pp. 1586-1594, 1989

[22] R. H. McKnight and H. K. Schoenwetter, "Capacitive sensors for voltage measurements in pulse power systems," in Conf. Rec. 1984 Sixteenth Power Modulator Symp., June 1984.

[23] R. Malewski, Y. Gervais, and M. Zwicky, "Resistor voltage divider for impulse measurements in SF test vessels," in Proc. Fourth Int. Symp. on High Voltage Engineering. Athens, Greece, Nat. Tech. Univ.. 1983.

[24] M. Kromholz, J. Doggett, K. H. Shoenbach, J. Gahl, C. Harjes, G Schaefer, and M. Kristiansen, "Nanosecond current probe for highvoltage experiments," Rev. Scientific Instrum., vol. 55, pp. 127-128, 1984 .

[25] H. D. Sutphin, "Subnanosecond high voltage attenuator," Rev. Scientific Instrum., vol. 43, pp. 1535-1536, 1972

[26] Z. Y. Lee, "Subnanosecond high-voltage two-stage resistive divider," Rev. Scientific Instrum., vol. 54, pp. 1060-1062, 1983 